\title{
MECHANISM OF INCREASED RENAL SODIUM EXCRETION FOLLOWING MANNITOL INFUSION IN MAN
}

\author{
By T. FRANKLIN WILLIAMS, 1 WALTER HOLLANDER, JR, 1 MAURICE B. \\ STRAUSS, ELSIE C. ROSSMEISL, AND REGINA MCLEAN \\ (From the Medical Service and Research Laboratory, Boston Veterans Administration Hospital, \\ The Department of Medicine, Boston University School of Medicine, and the De- \\ partment of Medicine, Tufts College Medical School, Boston, Mass.)
}

(Submitted for publication October 28, 1954; accepted December 29, 1954)

Mannitol, when given intravenously to normal human subjects or animals, shares with a number of other substances the property of promoting an increased rate of renal excretion of sodium, chloride, and water. The generally accepted hypothesis concerning the mechanism of this action is that mannitol exerts its effect directly on the renal tubules. The osmotic pressure of the mannitol within the tubular lumen is considered to interfere with the reabsorption of water. Sodium excretion is thought to be increased in the presence of the increased amounts of water in the tubule per unit time, either because reabsorption of sodium is limited by a maximum concentration difference for sodium which can be achieved between the tubular urine and the extracellular fluid (1-3) or because the contact of the sodium with the tubule cells is so brief that reabsorption is incomplete $(4,5)$. Evidence for a direct effect of mannitol on the renal excretion of salt and water is afforded by the experiments of Goodyer and Glenn (5). They injected large mannitol loads directly into one renal artery of dogs and produced prompt increases in salt and water excretion on the injected side. However another mechanism of action of mannitol in the intact animal is not excluded by these observations. Seldin and Tarail (6) have suggested that mannitol infusions may exert their effects outside the kidney by producing an expansion of extracellular volume and, when given in hypertonic solution, a contraction of intracellular volume, and thus indirectly altering some regulatory mechanism which increases the renal excretion of salt. This hypothesis has not thus far been excluded, and indeed was suggested as the probable mechanism of ac-

\footnotetext{
1 Present address : Department of Medicine, University of North Carolina School of Medicine, Chapel Hill, North Carolina.
}

tion of sodium chloride infusions in increasing renal sodium excretion by Green and Farah (7). They believe that the increased sodium intake influences sodium excretion primarily by establishing an osmotic pressure difference between extraand intracellular fluids.

In most studies $(1,4,6,8,9)$ hypertonic mannitol solutions (usually 25 per cent) have been injected. Such solutions would be expected, and have been calculated, to expand extracellular volume and contract intracellular volume. West, Kaplan, Fomon, and Rapoport (10) gave hypotonic mannitol solutions to hydrated dogs and found increased salt excretion. Here extracellular volume was expanded and although under such circumstances an absolute contraction of intracellular volume would appear unlikely, the calculated osmolarity of the plasma did rise during the mannitol infusion and therefore a relative decrease in intracellular water cannot be excluded.

Goodyer and Seldin (11) gave hypertonic mannitol solutions to two subjects during quiet standing and found less increase in salt excretion than normally occurs; to one standing, hydrated subject they gave a small amount (one liter) of hypotonic mannitol and found no increase in salt excretion. ${ }^{2}$ Recently it has also been shown that dogs on a low salt intake prior to mannitol infusion exhibit far less natriuresis than those on a high salt intake (12). These findings suggest that other factors which affect the renal reabsorption of sodium may affect sodium excretion during mannitol diuresis.

\footnotetext{
2 In the experiment with hypotonic mannitol, the glomerular filtration rate of the subject was about 25 per cent lower throughout the experiment-lying and standing-than is recorded for the same subject in other experiments.
} 
In an attempt to test further the possible role of volume changes in mannitol-induced saluresis, advantage has been taken of a previous demonstration in this laboratory that the infusion of two liters of hypotonic sodium chloride-sodium bicarbonate solution into normal, sitting, waterloaded subjects produces only slight increases in salt excretion (13). This is therefore a situation in which expansion of extracellular volume by an infused solution should not in itself significantly change salt excretion. In the experiments described here, a similar volume of an isotonic or slightly hypotonic mannitol solution has been administered to normal, sitting, water-loaded subjects. The resulting marked increase in salt excretion, when compared to the above control situation, indicates that mannitol induces saluresis by means other than expansion of extracellular volume. Since cellular overhydration was present throughout and the mannitol infusion did not raise extracellular fluid osmolarity contraction of intracellular volume can also be excluded from consideration.

\section{METHODS}

The subjects were three male adults admitted for the study of minor complaints and free from significant physical abnormalities. The procedure was the same as that used in the previous study in which hypotonic salinebicarbonate was infused (13) as follows: one to two hours after a breakfast low in salt, an "arterialized" blood sample was withdrawn; the subject voided and was weighed and then imbibed $1.5 \mathrm{~L}$. of tap water during the next one-half to one hour. The subject remained seated for the duration of the experiment except for standing to void and be weighed every half hour. After each weighing, he drank sufficient water to maintain body weight $1.5 \mathrm{Kg}$. greater than the initial weight. After a satisfactory water diuresis had been in progress for two hours, and had been reasonably constant for at least two periods, another blood sample was withdrawn and an intravenous infusion of two liters of a five per cent solution of mannitol, U.S.P., in water (270 to $275 \mathrm{mM}$ per L. by analysis) was commenced at a rate of approximately $20 \mathrm{ml}$. per min. The ingestion of water was continued so that at the conclusion of the infusion the body weight was maintained $3.5 \mathrm{Kg}$. above the initial weight." Blood was withdrawn at the conclusion of the infusion and again approximately two hours later, when the experiment was terminated. In one subject, $R$. $H$., the experiment was repeated a week later, using an infusion of

8 Subject J. McH. experienced fullness and some nausea near the end of the infusion and his total water load was allowed to decline slowly thereafter. the control solutions, i.e., two liters of a solution containing by analysis $112 \mathrm{mEq}$. sodium, $90 \mathrm{mEq}$. chloride, and $22 \mathrm{mEq}$. bicarbonate.

Analytic methods and formulae for calculation of changes in plasma volume were identical to those described in a recent report from this laboratory (14) except that serum proteins were done by the biuret reaction (15). Endogenous creatinine clearances were used as indices of rate of glomerular filtration. Mannitol analyses were made by the method of Smith, Finkelstein, and Smith (16) as modified by Elkinton (17). A number of specimens were also analyzed by a modification of the chromotropic acid method of MacFadyen (18). The results were in good agreement with those obtained by the Elkinton method. Serum and urine osmolal concentrations were determined with a Fiske freezing-point osmometer (Fiske Associates, Inc., 44 Bromfield St., Boston 8, Mass.). The machine was calibrated at the time of each set of analyses. Calibrations were made with sodium chloride solutions, with corrections for the activity of sodium chloride (International Critical Tables, 1928, Vol. IV) in such a way that a reading on the Fiske scale of " 1000 milliosmols per liter" represents a freezingpoint depression of $1.86^{\circ} \mathrm{C}$., "100 milliosmols per liter" represents a depression of $0.186^{\circ} \mathrm{C}$., etc. The calibra-

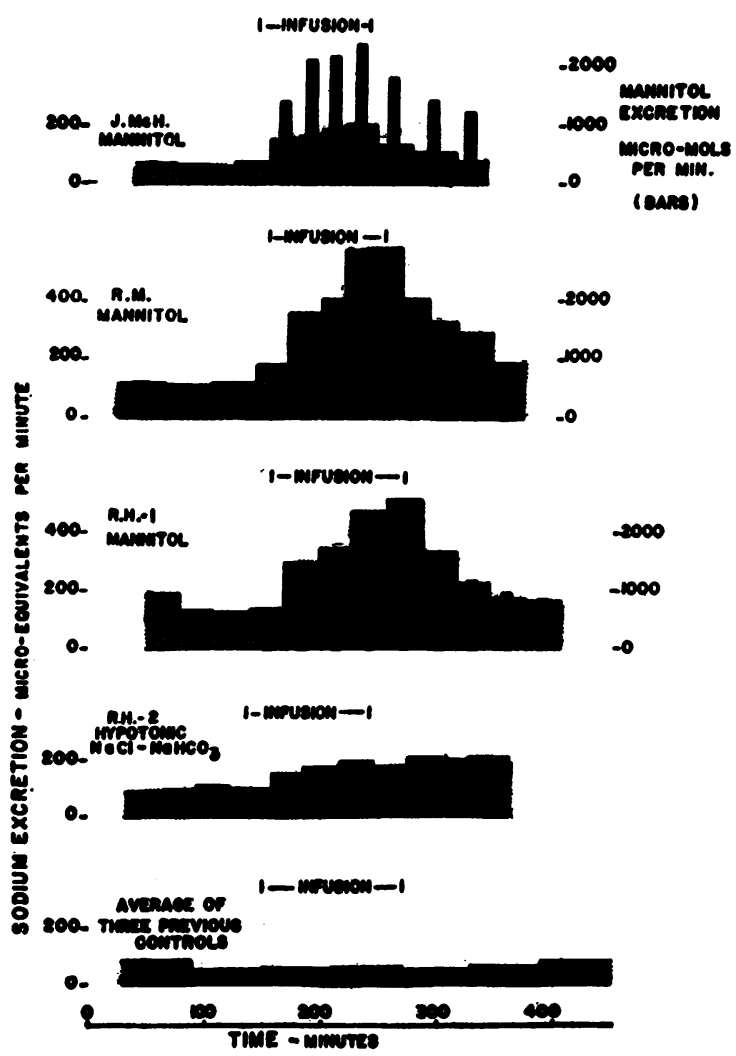

Fig. 1. The Emfect of Infusion of 5 Per Cent Mannitol or of Hypotonic Sodium Salts on the Renal Excretion of Sodium and Mannitol 


\begin{tabular}{|c|c|c|c|c|c|c|c|c|c|c|c|c|c|c|c|c|}
\hline \multirow{2}{*}{ 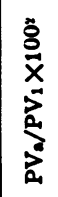 } & 总䜿 & ஜ̊ & छٌ & $\stackrel{\dot{m}}{\vec{\Xi}}$ & 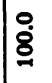 & $\stackrel{+}{a}$ & ธิ๋ & 웅 & ஜ̊ & 8 & : & 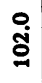 & ஜ̊ & \&े & $\stackrel{\circ}{0}$ & $\stackrel{\circ}{\Xi}$ \\
\hline & हैं & \&̊․ & $\stackrel{?}{\stackrel{9}{0}}$ & 离 & 迥 & ฯี & 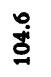 & 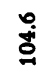 & 웅 & \%ั. & $\stackrel{\infty}{\Xi}$ & on. & 용 & $\stackrel{8}{8}$ & 8 & $\stackrel{m}{g}$ \\
\hline & 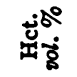 & $\stackrel{\infty}{9}$ & $\widehat{o}$ & \begin{tabular}{l}
$\infty$ \\
\multirow{j}{*}{} \\
\end{tabular} & $\overline{\mathfrak{j}}$ & ฟ & $\stackrel{m}{7}$ & $\stackrel{m}{7}$ & 号 & พี & $\stackrel{\infty}{j}$ & gे & 骂 & $\stackrel{\dot{\phi}}{\dot{\phi}}$ & 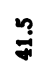 & $\dot{q}$ \\
\hline
\end{tabular}

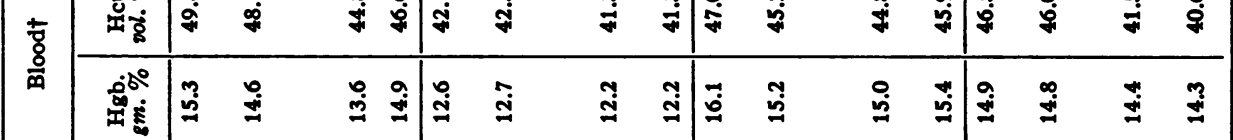

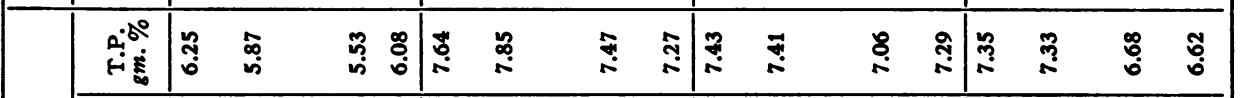

\begin{tabular}{|c|c|c|}
\hline نَّ & & 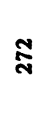 \\
\hline
\end{tabular}

票

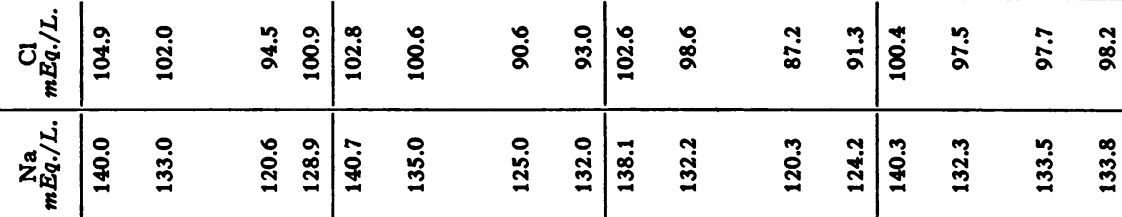

\begin{tabular}{|c|c|c|c|}
\hline 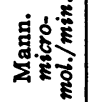 & 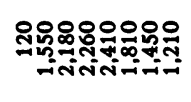 & 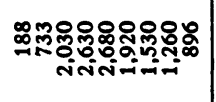 & 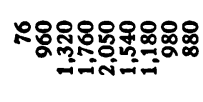 \\
\hline
\end{tabular}

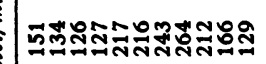

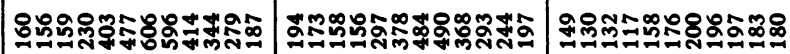

\begin{tabular}{|c|c|c|}
\hline โี & 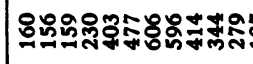 & 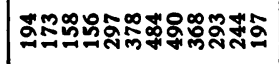 \\
\hline
\end{tabular}

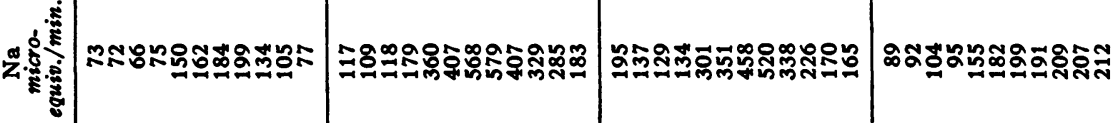

|

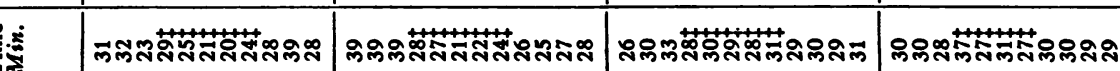

\begin{tabular}{|c|c|c|c|c|}
\hline 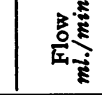 & | & 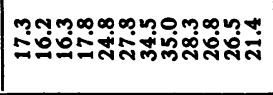 & 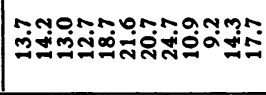 & 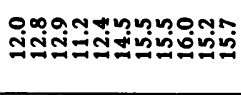 \\
\hline 苞: & 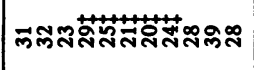 & 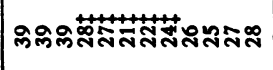 & 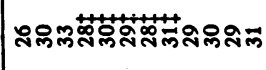 & 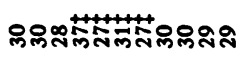 \\
\hline 营 & 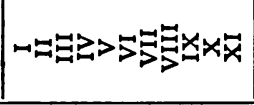 & - & 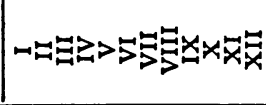 & - \\
\hline 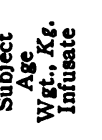 & 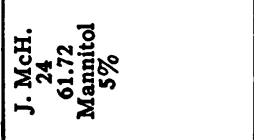 & 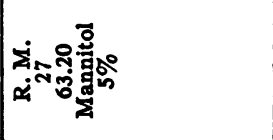 & 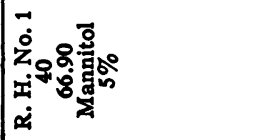 & 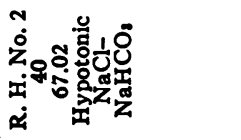 \\
\hline
\end{tabular}

\begin{tabular}{|c|c|c|c|c|}
\hline 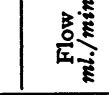 & | & 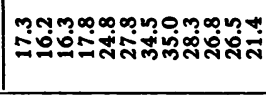 & 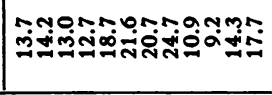 & 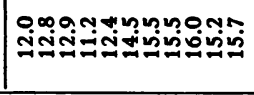 \\
\hline 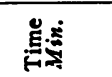 & 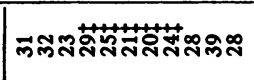 & ภิติ & 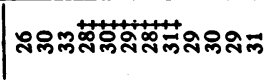 & ర్లంల్లజ \\
\hline 홓 & 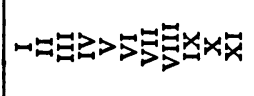 & 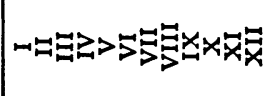 & - & 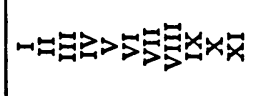 \\
\hline 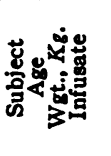 & 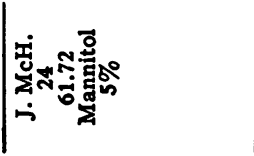 & 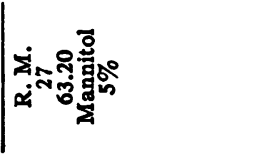 & 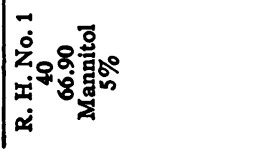 & 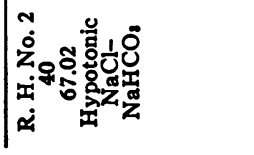 \\
\hline
\end{tabular}


tion has been checked with sucrose solutions of known molality and found to be accurate to \pm 2 per cent of the scale reading. Results are recorded for simplicity as "mOsm. per L." (Table I), although they are actually not determinations of osmolar concentration but of osmolal concentration, i.e., milliosmols per kilogram of serum water or urine water. No interpretation is made about the degree to which any given solute contributes to the total freezing-point depression.

\section{RESULTS}

The rate of urine flow and solute excretion, endogenous creatinine clearances, serum and blood analyses, and calculated changes in plasma volumes are given in Table I. Potassium analyses, though performed on all samples, are not included in the table because no changes of note in potassium concentration in plasma or its urinary excretion rate were observed.

As recorded in Table I and as shown graphically in Figure 1, the rate of sodium excretion began to increase promptly with the beginning of the mannitol infusion. The peak rate of sodium excretion in every subject was three to five times the preinfusion rate. In every subject the rate of sodium excretion closely paralleled the rate of mannitol excretion, during the infusion periods when mannitol and sodium excretion were increasing and during the post-infusion periods as well, when the excretion of both declined almost exponentially. Figure 2 demonstrates for the post-infusion periods in each subject that a straight-line relationship appears to exist between the rates of excretion of the two substances. The rate of excretion of sodium was not as well correlated with the total osmotic load in the urine (mOsm. per min.), with urine volume, or with mannitol concentration in the urine.

The results of infusing equal volumes of hypotonic sodium chloride-bicarbonate solution, as shown in the two lower graphs of Figure 1, were quite different. In the one such experiment reported here, R. H. No. 2, there was an increase in sodium and chloride excretion, but this increase began more slowly, was not as large as the in-

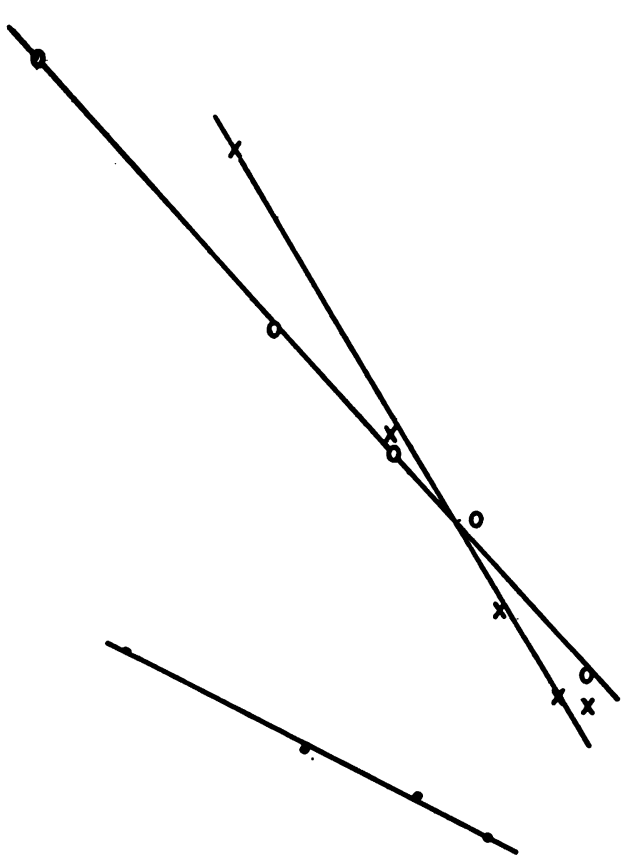

$-600$
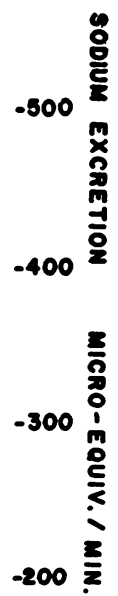

3000

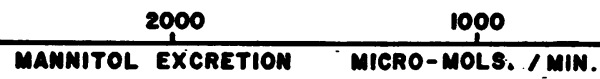

Fig. 2. Relationship Between Mannitol and Sodium Excretion Following Infusion of 5 Per Cent Mannitol

Open circles, R. M., closed circles, J. McH., crosses, R. H. No. 1. 
crease in sodium excretion which accompanied mannitol infusion in the same subject, and continued at a fairly constant rate for at least two hours after the infusion was completed. In the three control subjects previously reported, whose results are averaged in Figure 1 because they were so similar to each other, little increase in sodium excretion occurred during or after the chloridebicarbonate infusion in the sitting position.

Changes in plasma volume during the infusions, shown in Table I, and changes in chloride space, calculated by the formulae of Elkinton and Winkler (19) showed increases with the mannitol infusions that were slightly less than those found following the control infusions. In the mannitol experiments reported here, the maximum calculated increase in chloride space was 7 to 11 per cent; in the control experiment on R. H., the increase was 12.7 per cent; in the previously-reported controls, the increase was 12 to 16 per cent. This might be considered paradoxical since 550 milliosmols of mannitol were injected as contrasted to the 448 milliosmols of the sodium solution in the control studies. However the excretion of mannitol was so rapid that the maximum amount in the body at any time was less than 370 milliosmols. This maximum value obtained at the conclusion of the infusion by which time a minimum of 180 milliosmols of mannitol had already been excreted in the urine.

The total solute concentrations of the sera, estimated by freezing-point depression, did not change materially in any subject as a result of the mannitol infusion; see Table I.

The endogenous creatinine clearance exhibited no noteworthy changes throughout these experiments. During the mannitol infusion the serum sodium concentration fell 10 to $13 \mathrm{mEq}$. per L. in every subject, and rose again in the post-infusion periods. The filtered load of sodium was therefore falling during the time in which sodium excretion was rising, and rising when the sodium excretion was falling.

At the peak of the mannitol diuresis, urine flows had increased 8 to $10 \mathrm{ml}$. per min. above the initial flows. The highest flow recorded, $35 \mathrm{ml}$. per min., represented 21.7 per cent of the filtered water. The urine flow only roughly paralleled the rate of mannitol, sodium or total solute excretion. In Expt. R. H. No. 1 there appears to be an anti- diuresis despite the maintained water load, as may be seen from the fall in urine flow and rise in solute concentration in periods IX and X.

Associated with the large increase in rate of total solute excretion during the mannitol infusions, there was a rise in the total solute concentration in the urine. The "free water clearance," $\mathrm{CH}_{2} \mathrm{O}$, which is a measure of the degree to which solute reabsorption in excess of water reabsorption has taken place in the renal tubule, has been calculated by Wesson and Anslow's equation, $\mathrm{C}_{\mathrm{H}_{2} \mathrm{O}}=$ $\left(1-\frac{U_{\text {osm }}}{P_{\text {osm }}}\right) V(20)$. The maximal value of free water clearance attained by two subjects during mannitol diuresis was no higher than the maximal value attained during the preceding periods of water diuresis alone. The third subject, R. M., showed a free water clearance of $18.0 \mathrm{ml}$. per min. during the mannitol infusion, in contrast to a maximal value of $13.7 \mathrm{ml}$. per min. during the preceding water diuresis.

\section{DISCUSSION}

It is unlikely that the greatly increased salt excretion induced by mannitol infusion in these experiments was due entirely to changes in extracellular volume since an equal or greater expansion of extracellular volume by a hypotonic salt infusion in the control experiments was associated with relatively small increases in salt excretion.

Furthermore, in every subject the sodium excretion began rising promptly in the first collection period after the mannitol infusion was begun, at a time when the extracellular volume had been increased by less than a liter, and by less than 500 $\mathrm{ml}$. in subject R. M. Similarly the excretion of sodium began to decline promptly with the decline in mannitol excretion, at a time when changes in extracellular volume between successive periods must have been very small.

Seldin and Tarail as well as Green and Farah suggested that cellular dehydration, as a result of elevated extracellular osmolarity, might stimulate sodium excretion. This possibility is excluded in the present experiments both because of the maintained state of overhydration and because the serum osmolarity was unchanged by the isotonic or slightly hypotonic mannitol infusions (see Table I). 
Although the water turnover was greater in the mannitol than in the control experiments (i.e., the rate of water ingestion and of water excretion was greater) there was never a larger water load retained in the body such as Leaf, Bartter, Santos, and Wrong (21) have associated with increased urinary electrolyte excretion.

It seems most likely that the mannitol exerts its saluretic effect in the experiments in normal human subjects recorded here by a direct renal tubular action. The rate of renal excretion of sodium appears to be directly proportional, under the conditions of these experiments, to the rate of excretion of the mannitol, which in turn is directly proportional to the filtered load of mannitol (22). However, it will be noted that the slopes and intercepts of the lines relating mannitol and sodium excretion (Figure 2) are not identical in the three subjects, indicating that other factors than the mannitol excretion rate are active in regulating sodium excretion, as has been observed previously $(11,12)$.

Mannitol, as a non-electrolyte which probably does not cross cell membranes in significant amounts, would be expected to affect the equilibria of diffusible electrolytes as well as water across the cell membranes which are in contact with the mannitol. Although this effect will be greatest where the mannitol concentration is highest, i.e., in some portion of the renal tubule, it will theoretically be true of any body cell. The actual effect of mannitol solutions on body cells remains to be investigated.

In two subjects, as noted in the results, solute reabsorption without water reabsorption (free water clearance) apparently reached a maximal rate, uninfluenced by rising solute loads. As the rate of solute excretion rose, the urine solute concentration necessarily rose. In the third subject, higher free water clearances were associated with the increased solute loads of the mannitol diuresis. A similar finding has been noted and discussed by Welt, Young, Thorup, and Burnett (23). It should be borne in mind that such changes could always be due to variations in endogenous anti-diuretic hormone secretion, a factor which cannot be adequately excluded by present methods. Evidence of varying anti-diuretic hormone activity in Experiment R. H. No. 1 was noted in the results.

\section{SUMMARY AND CONCLUSIONS}

The intravenous infusion of an isotonic or slightly hypotonic solution of mannitol in sitting, water-loaded subjects leads to a marked increase in the urinary excretion of sodium and chloride although the filtered load of sodium presented to the renal tubules is actually diminished.

Since comparable expansion of extracellular fluid volume by hypotonic sodium solutions fails to produce similar increases in sodium and chloride excretion, it appears unlikely that the mannitol effect derives from expansion of extracellular fluid volume. In view of the fact that cellular overhydration was already present before the mannitol infusion was commenced, and the fact that isotonic or slightly hypotonic mannitol infusion does not increase extracellular osmolarity, cellular dehydration does not seem to be a factor.

The observations lend support to the hypothesis that the main site of action of mannitol (and allied materials) in increasing urinary sodium and chloride excretion is in the renal tubule.

\section{REFERENCES}

1. Wesson, L. G., Jr., and Anslow, W. P., Jr., Excretion of sodium and water during osmotic diuresis in the dog. Am. J. Physiol., 1948, 153, 465.

2. Wesson, L. G., Jr., Anslow, W. P., Jr., and Smith, $\mathrm{H}$. W., The excretion of strong electrolytes. Bull. New York Acad. Med., 1948, 24, 586.

3. Smith, H. W., The Kidney: Structure and Function in Health and Disease. New York, Oxford Univ. Press, 1951, pp. $308 \mathrm{ff}$.

4. Relman, A. S., Goodyer, A. V. N., and Peterson, E. R., Effect of mannitol on salt excretion during water diuresis. J. Applied Physiol., 1949, 1, 601.

5. Goodyer, A. V. N., and Glenn, W. W. L., Excretion of solutes injected into the renal artery of the dog. Am. J. Physiol., 1952, 168, 66.

6. Seldin, D. W., and Tarail, R., Effect of hypertonic solutions on metabolism and excretion of electrolytes. Am. J. Physiol., 1949, 159, 160.

7. Green, D. M., and Farah, A., Influence of sodium load on sodium excretion. Am. J. Physiol., 1949, 158, 444.

8. Rapoport, S., Brodsky, W. A., West, C. D., and Mackler, B., Urinary flow and excretion of solutes during osmotic diuresis in hydropenic man. Am. J. Physiol., 1949, 156, 433.

9. Rapoport, S., and West, C. D., Excretion of sodium and potassium during osmotic diuresis in the hydropenic dog. Am. J. Physiol., 1950, 163, 175.

10. West, C. D., Kaplan, S. A., Fomon, S. J., and Rapoport, S., Urine flow and solute excretion dur- 
ing osmotic diuresis in hydrated dogs: role of distal tubule in the production of hypotonic urine. Am. J. Physiol., 1952, 170, 239.

11. Goodyer, A. V. N., and Seldin, D. W., The effects of quiet standing on solute diuresis. J. Clin. Invest., 1953, 32, 242.

12. Simmons, D. H., Hervey, R. B., and Hoshiko, T., Effect of sodium intake on sodium loss due to mannitol diuresis-an empirical test for renal sodium-retaining activity. Am. J. Physiol., 1954, $178,182$.

13. Strauss, M. B., Davis, R. K., Rosenbaum, J. D., and Rossmeisl, E. C., Production of increased renal sodium excretion by the hypotonic expansion of extracellular fluid volume in recumbent subjects. J. Clin. Invest., 1952, 31, 80.

14. Strauss, M. B., Davis, R. K., Rosenbaum, J. D., and Rossmeisl, E. C., "Water diuresis" produced during recumbency by the intravenous infusion of isotonic saline solution. J. Clin. Invest., 1951, 30, 862.

15. Gornall, A. G., Bardawill, C. J., and David, M. M., Determination of serum proteins by means of the biuret reaction. J. Biol. Chem., 1949, 177, 751.

16. Smith, W. W., Finkelstein, N., and Smith, H. W., Renal excretion of hexitols (sorbitol, mannitol, and dulcitol) and their derivatives (sorbitan, isomannide, and sorbide) and of endogenous creatininelike chromogen in dog and man. J. Biol. Chem., 1940, 135, 231.

17. Elkinton, J. R., The volume of distribution of mannitol as a measure of the volume of extracellular fluid, with a study of the mannitol method. J. Clin. Invest., 1947, 26, 1088.

18. MacFadyen, D. A., Estimation of formaldehyde in biological mixtures. J. Biol. Chem., 1945, 158, 107.

19. Elkinton, J. R., and Winkler, A. W., Transfers of intracellular potassium in experimental dehydration. J. Clin. Invest., 1944, 23, 93.

20. Wesson, L. G., Jr., and Anslow, W. P., Jr., Effect of osmotic and mercurial diuresis on simultaneous water diuresis. Am. J. Physiol., 1952, 170, 255.

21. Leaf, A., Bartter, F. C., Santos, R. F., and Wrong, O., Evidence in man that urinary electrolyte loss induced by pitressin is a function of water retention. J. Clin. Invest., 1953, 32, 868.

22. Smith, H. W., op. cit, pp. 204 ff.

23. Welt, L. G., Young, D. T., Thorup, O. A., Jr., and Burnett, C. H., Renal tubular phenomena under the influence of a carbonic anhydrase inhibitor. (Abstract). Am. J. Med., 1954, 16, 612. 